\title{
ANALISIS STRUKTUR TANGGA PROYEK PEMBANGUNAN RSUD CIDERES MAJALENGKA
}

\author{
Abdul Kholiq, \\ Teknik Sipil Fakultas Teknik Universitas Majalengka \\ Choliq_fastac@yahoo.co.id
}

\begin{abstract}
Abstraksi
Penelitian ini dilakukan untuk menganalisa struktur tangga yang merupakan sebuah konstruksi yang dirancang untuk menghubungi dua tingkat vertikal yang memiliki jarak satu sama lain, dan dalam laporan ini juga akan membahas standart-standart perencanaan tangga yang diperuntukan untuk rumah sakit. Type tangga yang digunakan adalah type $U$ karena paling efisien, tidak terlalu melebar atau tidak membutuhkan tempat yang luas untuk penempatannya. Struktur Tangga terdapat Untuk tinggi dan lebar anak tangga yang sangat menentukan kenyamanan, sehingga orang yang naik tidak cepet lelah dan orang yang turun tidak mudah tergelincirt idak sesuai dengan perhitungan atau standar ideal dari perencanaan tinggi dan lebar pada suatu anak tangga $2 t+l=2 *(18)+30=66 \mathrm{~cm}$ yang harusnya adalah 60-65 cm. Dengan injakan $30 \mathrm{~cm}$, tanjakan $18 \mathrm{~cm}$, dan tinggi total keseluruhan adalah $8 \mathrm{~m}$ maka Total anak tangga adalah 42 buah Anak Tangga, dari nilai tersebut terdapat selisih maka beda tinggi anak tangga di letakan pada satu anak tangga yang paling bawah atau paling atas. Dalam perhitungan kebutuhan tulangan pada tangga dan bordes dengan menggunakan D13-200 dibutuhkan enam tulangan untuk tangga dan lima belas tulangan untuk bordes.Dengan luas tulangan yang di dapatkan dari pergitungan tangga dan bordes hasil yang di dapat aman.
\end{abstract}

Kata Kunci: Bordes, Konstruksi Struktur, Tangga

\section{PENDAHULUAN}

\section{A. Latar Belakang}

Di dalam suatu bangunan, tangga merupakan struktur yang merupakan komponen terpenting dalam penggunaannya. Suatu gedung bertingkat tidak akan dapat digunakan secara optimal, apabila tidak ada struktur tangga didalamnya.

Pada analisis yang akan dilakukan, perhitungan akan kebutuhan tulangan pada pelat tangga ini akan didasarkan pada peraturan SNI 03-2847-2002.

\section{B. Tujuan Penelitian}

1. Menganalisi pelaksanaan dan Perhitungan Penulangan Pelat Tangga.

2. Mengetahui Penentuan Tebal Pelat Tangga dan Bordes.

3. Mengetahui ketentuan dan standar untuk : Tinggi antar lantai, Tinggi Antrede, Jumlah anak tangga, Kemiringan tangga, Tebal pelat beton, Tinggi Optrede, Lebar bordes, Lebar anak tangga, Tebal selimut beton, Tebal pelat tangga

\section{Batasan Masalah}

Dalam penelitian ini terdapat batasan masalah yakni hanya akan mengkaji Struktur Tangga yang meliputi :

1. Perhitungan tulangan yang dibutuhkan, perhitungan jumlah anak tangga yang dibutuhkan,

2. Standar kemiringan dalam perencanaan tangga khususnya untuk tangga di Rumah Sakit.

Dan tidak membahas Dokumen pelelangan, Administrasi Kontrak, rencana anggaran biaya, manajemen waktu, dan penjadwalan.

\section{Waktu Dan Tempat Pelaksanaan Penelitian}

Penelitian ini dilaksanaka pada proyek pembangunan gedung baru RSUD Cideres yang 
meliputi gedung poliklinik eksekutif, perawatan vip, diagnostic center dan kantor tepatnya di Jalan Raya Cideres No. 180, Bojong Cideres, Dawuan, Kabupaten Majalengka, Provinsi Jawa Barat.

\section{TINJAUAN \\ UMUM PENELITIAN}

A. Data Proyek

Nama Proyek; Pembangunan RSUD Cideres Majalengka. Lokasi Proyek; Jalan Raya Cideres Kadipaten No. 180 Bojong Cideres Dawuan. Luas Bangunan Total; $1188 \mathrm{~m}^{2}$. Pemilik Proyek; RSUD Cideres Majalengka Konsultan Perencana: PT. DELLASONTA MOULDING INTERNATIONAL, Pengawas: PT. MODULE TRI ARBA Kontraktor Utama: PT. MONTEKAR AGUNG PERKASA

\section{B. Data Pengalaman Perusahaan}

1. Pembangunan Gedung Bedah Central, Perawatan Bedah, Kandungan / Kebidanan dan Anak, Instalasi Loundry dan Gizi, Laboratorium, Lokasi Desa Bandorasa Wetan Kec. Cilimus Kab. Nilai Kontrak Rp.5.299.272.000, Tahun 2007.

2. Pembangunan Terminal Tipe A di Kuningan Tahap IV. LOkasi Desa Kertawangunan Kec. Sindangagung Kab. Kuningan Rp.10.427.525.000, Tahun 2007

Sumber : Data Kontraktor

\section{LANDASAN TOERI}

A. Konstruksi tangga

Konstruksi Tangga harus kuat dan stabil, karena sebagai jalan penghubung ke lantai tingkat. Menurut peraturan pembebanan Indonesia untuk gedung, 1983, bahwa beban ditangga lebih besar dari beban pada pelat lantai.

- Untuk bangunan rumah tinggal $=250 \mathrm{~kg} / \mathrm{m}^{2}$

- Dan bangunan umum diambil $=300 \mathrm{~kg} / \mathrm{m}^{2}$

Konstruksi tangga dapat menjadi satu dengan rangka bangunannya, jika terjadi ada penurunan bisa menyebabkan sudut kemiringan tangga berubah, Jika konstruksi tangga tersendiri artinya terpisah dengan struktural rangka bangunan, dibuatkan pondasi tersendiri rangka tangga tidak menempel pada dinding diberi sela $\pm 5 \mathrm{~cm}$.Bidang momen yang terjadi pada ibu tangga.

\section{B. Bahan Tangga}

Dapat dari bahan; kayu, beton bertulang,baja, batu alam.

- Tangga kayu;

Mudah dikerjakan, harga cukup murah, bentuk bahan alami menambah kesejukan suasana ruang.

- Tangga beton bertulang;

Konstruksinya kuat dan awet, tidak cepat rusak, dapat berumur panjang, bahan tahan api. Dapat dipasang di bangunan umum atau bangunan tingkat rendah atau sampai dengan 4 (empat) lantai.

\section{Tipe Tangga}

Berdasar bentuknya, Tipe tangga ada 2 macam yaitu tangga lurus dan spiral. Penjelasannya sebagai berikut :

1. Tangga lurus; Tangga jenis ini memiliki desain tangga sebagai berikut:
a. Tangga $\mathrm{L}$
b. Tangga Dobel L
c. Tangga $\mathrm{U}$
d. Tangga Belok
e. Tangga Spiral

\section{Hal Penting Dalam Perencanaan Tangga}

Beberapa hal yang harus diterapkan dalam merencanakan konstruksi tangga secara umum yaitu :

1. Direncanakan dan dipasang berdasarkan zoning yang mudah dijangkau oleh setiap orang

2. Pada daerah tangga harus mendapat penerangan yang cukup terutama pada siang hari

3. Tangga mudah dijalani atau digunakan

4. Kuat, nyaman, sederhana dan layak untuk dipakai.

5. Pada saat digunakan tangga tersebut terasa nyaman, menyenangkan dijalani, maka ukuran Optrade (Tanjakan) dan Aantrede (Injakan) harus sebanding. 
Ukuran ideal dalam perencanaan konstruksi sebuah tangga yang memungkinkan sebagai berikut :

- Untuk dilalui 1 orang lebar digunakan ukuran $\pm 80 \mathrm{~cm}$

- Untuk dilalui 2 orang lebar digunakan ukuran $\pm 120 \mathrm{~cm}$

- Untuk dilalui 3 orang lebar digunakan ukuran $\pm 160 \mathrm{~cm}$

E. Syarat Ukuran Dalam Perencanaan Tangga

\section{Lebar Tangga}

Lebar tangga yang biasa digunakan (dan diijinkan) dalam bangunan rumah tinggal adalah minimal $80 \mathrm{~cm}$ (tangga utama, bukan tangga service). Sedangkan untuk tangga service minimal lebarnya $60 \mathrm{~cm}$.

Lebar tangga minimal untuk 1 orang adalah $60 \mathrm{~cm}$. Maka untuk desain tangga:

- Untuk 1 orang

$$
\begin{aligned}
& =60 \mathrm{~cm} \\
2 \times 60 & =120 \mathrm{~cm} \\
3 \times 60 & =180 \mathrm{~cm}
\end{aligned}
$$

- Untuk 2 orang

- Untuk 3 orang

Lebar tangga tersebut adalah lebar tangga bersih. Tidak termasuk railling dan atau batas dinding.
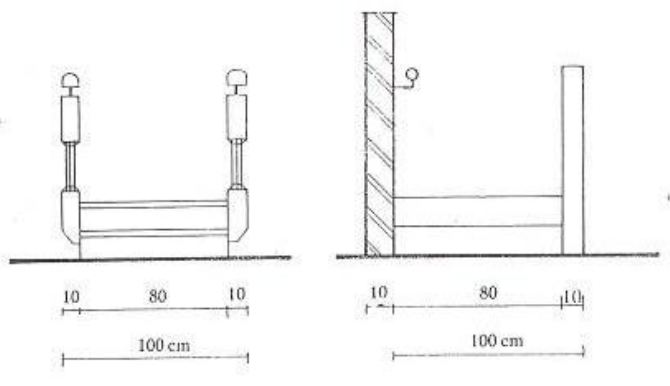

Gambar 1 Detail Lebar pada Tangga

Perhitungan kebutuhan tangga untuk bangunan umum dihitung $60 \mathrm{~cm}$ lebar tangga untuk tiap 100 orang. Misalnya bangunan teater dengan kapasitas 1.000 orang membutuhkan lebar tangga $1.000 / 100 \times 60 \mathrm{~cm}=6 \mathrm{~m}$. Untuk itu dapat dipakai 1 tangga denga lebar $6 \mathrm{~m}$ atau dua buah tangga dengan lebar masing-masing $3 \mathrm{~m}$.

Namun demikian apabila masih dimungkinkan sebaiknya menggunakan lebar minimal $1.20 \mathrm{~cm}$, yang merupakan lebar tangga standart keamanan/keadaan darurat (emergency stairs).

\section{Kemiringan Tangga}

Pada dasarnya kemiringan tangga dibuat tidak terlalu curam agar memudahkan orang naik tanpa mengeluarkan banyak energi, tetapi juga tidak terlalu landai sehingga tidak akan menjemukan dan memerlukan banyak tempat karena akan terlalu panjang. Kemiringan tangga yang wajar dan biasa digunakan adalah berkisar antara $25^{\circ}-42^{\circ}$. untuk bangunan rumah tinggal biasa digunakan kemiringan $38^{\circ}$.

\section{Lebar Dan tinggi Anak Tangga}

Satu langkah manusia arah datar adalah 60 $65 \mathrm{~cm}$, sedangkan untuk melangkah naik perlu tenaga 2 kali lebih besar daripada melangkah datar. Oleh karena itu, perbandingan yang baik adalah

\section{$(L+2 T)=60 \operatorname{sid} 65 \mathrm{~cm}$}

$\mathrm{L}=$ lebar anak tangga (lebar injakan = aantrede)

$\mathrm{T}=$ tinggi anak tangga (tinggi tanjakan = optrade)

Biasanya,

T berkisar antara $14-20 \mathrm{~cm}$ agar masih terasa mudah di daki

L berkisar antara 22,5 - $30 \mathrm{~cm}$ agar tapak sepatu dapat berpijak dengan baik.

\section{Jumlah Anak Tangga}

Jumlah anak tangga dalam satu tangga diusahakan tidak lebih dari 12 buah apabila lebih dianjurkan untuk menggunakan bordes. Hal ini untuk mencapai kenyamanan pengguna terutama penyandang cacat dan orang tua.

Kalau keadaan memaksa, misalnya karena keterbatasan ruangan yang ada, maka dimungkinkan jumlahnya maksimal 16 anak tangga, hal ini mengacu kondisi maksimal kemampuan (kelelahan) tubuh manusia.

\section{Jumlah anak tangga $=$ tinggi floor to floor $-1 \mathrm{~cm}$

$$
T
$$

Untuk menghindari kecelakaan, apabila dimungkinkan sebaiknya anak tangga dibuat seragam ukurannya, baik tinggi ataupun lebarnya. Apabila tidak dimungkinkan, anak tangga yang berbeda ukurannya diletakkan pada bagian paling bawah (antisipasi keamanan). 


\section{Bordes}

Bordes adalah bagian datar (anak tangga yang dilebarkan) pada ketinggian tertentu yang berfungsi untuk beristirahat. Bordes tangga dapat dibagi menjadi 3 model dengan aturan ukuran yang berbeda, yaitu: bordes tangga lurus, bordes tangga $\mathrm{L}$ dan bordes tangga $\mathrm{U}$.

\section{Sandaran Tangan}

Sandaran tangan (Railling) tangga perlu dibuat untuk kenyamanan dan keselamatan pengguna tangga, terutama tangga bebas, yang tidak diapit oleh dinding. Tinggi yang biasa digunakan adalah antara $80-100 \mathrm{~cm}$. Railing harus dibuat dari bahan yang halus/licin, sehingga nyaman dan tidak melukai tanggan. Railing biasanya bertumpu pada baluster (tiang penyangga).

\section{Ruang Tangga dan Kontruksi Tangga}

Ruang tangga adalah ukuran modul ruang yang dibutuhkan untuk perletakan tangga. Ruang tangga harus cukup cahaya dan ventilasi.

Ukuran ruang tangga ditentukan oleh jumlah anak-tangga dan bentuk tangganya.Sebagai contoh dari hasil hitungan di atas. dengan 3 macam bentuk tangga, dipakai untuk bangunan rumah tinggal. dengan lebar $100 \mathrm{~cm}$, jumlah anak-tangga 17 buah dan dengan memakai bordes, maka ukuran ruang tangganya adalah:

\section{F. Pekerjaan Struktur Tangga}

Bagian - bagian dari struktur tangga yaitu Pondasi Tangga berfungsi sebagai dasar tumpuan landasan agar tangga tidak mengalami penurunan, pergeseran. Pondasi tangga bisa dari pasangan batu kali, beton bertulang atau kombinasi dari kedua bahan dan pada dibawah pangkal tangga harus diberi balok anak sebagai pengaku pelat lantai, agar lantai tidak menahan beban terpusat yang besar.

Pondasi tangga bisa dari pasangan batu kali, beton bertulang atau kombinasi dari kedua bahan dan pada dibawah pangkal tangga harus diberi balok anak sebagai pengaku pelat lantai, agar lantai tidak menahan beban terpusat yang besar.

\section{METODE DAN TEKNIK PENGUNGKAPAN}

Metode yang dilakukan dalam pengumpulan data untuk penyusunan laporan kerja praktik ini adalah sebagai berikut :

1. Observasi, yaitu melihat dan mengamati serta mencatat secara langsung kegiatan yang sedang berlangsung dilapangan guna mendapatkan data yang berhubungan dengan proses pembangunan yang sedang berlangsung.

2. Wawancara, yaitu melakukan tanya jawab dengan orang - orang yang terlibat dalam pekerjaan dilapangan seperti pelaksana, pengawas, mandor, dan para pekerja lainnya.

3. Kepustakaan (Literatur), yaitu membaca buku - buku tentang pedoman pelaksanaan dan pengawasan pembangunan gedung.

4. Gambar kerja dan data lainnya yang diperoleh dari kontraktor selama penelitian

5. Dokumentasi kegiatan dilapangan.

6. Referensi yang relevan dalam penelitian ini

\section{ANALISA STRUKTUR TANGGA}

\section{A. Tinjauan Umum}

Tangga merupakan suatu komponen struktur yang terdiri dari plat, bordes dan anak tangga yang menghubungkan satu lantai dengan lantai di atasnya. Tangga mempunyai bermacammacam bentuk tangga yaitu tangga lurus, tangga tangga 1, tangga $\mathrm{u}$, tangga putar.

Melihat dari kebutuhan dan luas dari bangunan proyek pembangunan RSUD Cideres ini menggunakan tipe Tangga Berbalik Arah dengan model $\mathrm{U}$, dilihat dari manfaatny pemilihan tipe tangga ini adalah tidak membutuhkan ruang yang cukup luas dalam pelaksanaannya.

\section{B. Data Material Tangga}

Tangga yang digunakan adalah tangga bebahan beton bertulang karena Konstruksinya kuat dan awet, tidak cepat rusak, dapat berumur panjang, bahan tahan api. Berikut Beberapa data material yang digunakan dalam kontruksi tangga:

- Spesifikasi Beton 
- Berat Jenis beton bertulang $=2400 \mathrm{~kg} / \mathrm{m}^{3}$

- Mutu Beton $=\mathrm{K}-250$

Maka Kuat Tekan Beton ( fc')

$=\mathrm{K} * 0,083$

$=250 * 0,083$

$=20,75 \approx 21 \mathrm{Mpa}$

- Kuat Leleh ( fy ) $=360 \mathrm{Mpa}$

- $\beta 1$ ( Faktor Koreksi ) $=0,85($ Karena fc' $<30$ Mpa $)$

- Tulangan Utama $=\phi \mathrm{u}-13$

- Tulangan Sengkang $=\phi u-8$

- Selimut Beton (p) $=0,2 \mathrm{~cm}$

\section{Perhitungan Tangga}

- Data perencanaan tangga :

- Jenis Tangga Tangga tipe U / Tangga Balik

- Tinggi antar lantai : $400 \mathrm{~cm}$

- Lebar Tangga (b) $: 120 \mathrm{~cm}$

- Optrade / Tanjakan (t) $\quad: 18 \mathrm{~cm}$

- Antrede / Injakan (m) $: 30 \mathrm{~cm}$

- Kemiringan $(\alpha)$ $: 31,22^{\circ}$

- Tinggi optrade dan Lebar antrade :

Jumlah Optrade / Tanjakan

$=\frac{\text { Tinggi Antar Lantai }}{\text { Jarak Optrade }}$

$=\frac{400}{18}=22,22$ Buah

Jumlah Antrade / Injakan

$=$ Jumlah Optrade -1

$=22,22-1$

$=21,22$ Buah

Perhitungan ideal dari perencanaan tinggi dan lebar pada suatu anak tangga adalah $2 \mathrm{t}+\mathrm{m}$ $=2 *(18)+30=66 \mathrm{~cm}$ ( dari perhitungan dan acuan diatas satu langkah datar idealnya 60 - 65 $\mathrm{cm}$ maka pada perencanaan ini terlalu melebihi tingkat idealnya).

Maka Jumlah anak tangga

$=($ Tinggi Tangga $/$ Optrade $)-1$
$=(400 / 18)-1$

$=21,22$ Buah $=21$ buah

Dari jumlah diatas Penulis bisa simpulkan bahwa jumlah total anak tangga adalah dua puluh satu buah anak tangga untuk lantai satu ke lantai dua, untuk lantai dua kelantai tiga jumlahnya sama maka total keseluruhan anak tangga adalah empat puluh dua buah, dari nilai tersebut terdapat selisih maka beda tinggi anak tangga di letakan pada satu anak tangga yang paling bawah atau paling atas.

\section{Pembebanan Tangga (Berdasarkan SNI 03-2847-2002 )}
Data : Tinggi Antar Lantai $\quad=400 \mathrm{~cm}$
Lebar Tangga $(\mathrm{b}) \quad=120 \mathrm{~cm}$
Optrade $(\mathrm{t}) \quad=18 \mathrm{~cm}$
Antrade $(\mathrm{m}) \quad=30 \mathrm{~cm}$
Tebal plat tangga $\quad=20 \mathrm{~cm}$

\section{Pelat Tangga}

a. Tinggi Plat Tangga (ht)

$=\frac{1}{20}\left(0,4+\frac{\mathrm{fy}}{700}\right) \mathrm{x}$ Tinggi Lantai

$=\frac{1}{20}\left(0,4+\frac{360}{700}\right) \times 400 \mathrm{~cm}$

$=18,28 \mathrm{~cm}$

$=18 \mathrm{~cm}$

b. Jumlah Anak Tangga tiap meter

$=\frac{1}{\text { Antrede }}$

$=\frac{1}{30}$

$=3,33$ Buah

c. Berat satu buah anak tangga

$=(1 / 2 \times t \times m) \times b \times \gamma$ beton

$=(1 / 2 \times 18 \times 30) \times 120 \times 24$

$=0,778 \mathrm{Kn}$ 


\section{Berat Tangga Tiap meternya

$$
\begin{aligned}
& =\text { Anak Tangga } / \mathrm{m} \times \text { Berat satu buah } \\
& =3,33 \times 0,778 \\
& =2,6 \mathrm{kN} / \mathrm{m}^{3}
\end{aligned}
$$

\section{Beban Mati pelat tangga}

\section{a. Berat pelat tangga}

$=($ Tebal pelat $+0,10 / 2) \times \gamma$ beton bertulang

$=(0,2+0,10 / 2) \times 2400$

$$
=600 \mathrm{~kg} / \mathrm{m}^{2}
$$

\section{b. Berat Spesi}

$=$ Jarak spesi $(\mathrm{cm}) \times 21 \mathrm{~kg} / \mathrm{m}^{2}$

$=2 \times 21 \mathrm{~kg} / \mathrm{m}^{2}$

$=42 \mathrm{~kg} / \mathrm{m}^{2}$

\section{c. Berat tegel Kramik}

$=$ tebal tegel kramik x ukuran tegel kramik

$$
\begin{gathered}
=0,5 \times 24 \mathrm{~kg} / \mathrm{m}^{2} \\
=12 \mathrm{~kg} / \mathrm{m}^{2}
\end{gathered}
$$

Maka jumlah beban mati pada pelat tangga adalah

$$
\begin{aligned}
\mathrm{WD}= & \text { Berat Plat Tangga }+ \text { Berat Spesi }+ \\
& \text { Berat Tegel Keramik } \\
= & 600+42+12 \\
= & 654 \mathrm{~kg} / \mathrm{m}^{2}
\end{aligned}
$$

\section{Beban Hidup pelat tangga}

$$
\mathrm{WL}=1 \times 300 \mathrm{~kg} / \mathrm{m}^{2}=300 \mathrm{~kg} / \mathrm{m}^{2}
$$

\section{Beban Ultimate}

$$
\begin{aligned}
\mathrm{Wu} & =1,2 \times \mathrm{WD}+1,6 \times \mathrm{WL} \\
& =1,2(654)+1,6(300) \\
& =1264,8 \mathrm{Kg} / \mathrm{m}
\end{aligned}
$$

\section{Pelat Bordes}

Beban mati pelat bordes

a. Berat tegel Kramik

$=$ Tebal tegel kramik x ukuran tegel kramik

$=0,5 \times 24 \mathrm{~kg} / \mathrm{m}^{2}$

$=12 \mathrm{~kg} / \mathrm{m}^{2}$ b. Berat Spesi

$=$ Jarak spesi $(\mathrm{cm}) \times 21 \mathrm{~kg} / \mathrm{m}^{2}$

$=2 \times 21 \mathrm{~kg} / \mathrm{m}^{2}$

$=42 \mathrm{~kg} / \mathrm{m}^{2}$

c. Berat pelat bordes

$=$ Tebal pelat $\mathrm{x} 1 \mathrm{x} \gamma$ beton bertulang

$=0,2 \times 1 \times 2400$

$=480 \mathrm{~kg} / \mathrm{m}^{2}$

Maka jumlah beban mati pada pelat bordes adalah

$\mathrm{WD}=$ Berat Tegel Keramik + Berat Besi + Berat Plat Bordes

$$
=12+42+480=534 \mathrm{~kg} / \mathrm{m}^{2}
$$

Beban Hidup pelat Bordes

$\mathrm{WL}=1 \times 300 \mathrm{~kg} / \mathrm{m}^{2}=300 \mathrm{~kg} / \mathrm{m}^{2}$

Beban Ultimate

$\mathrm{Wu}=1,2 \mathrm{WD}+1,6 \mathrm{WL}$

$=1,2(534)+1,6(300)$

$=1120,8 \mathrm{Kg} / \mathrm{m}$

E. PERHITUNGAN TANGGA DAN BORDES

TULANGAN

1. Perhitungan Tulangan Tangga

Data

$$
\begin{aligned}
\mathrm{b} & =1200 \mathrm{~mm} \\
\mathrm{~h} & =200 \mathrm{~mm} \\
\mathrm{~d} \quad & =\mathrm{h}-\mathrm{p}-1 / 2 \text { Dtul }-1 / 2 \text { Dsengkang } \\
& =200-20-1 / 213-1 / 28 \\
& =169,5 \mathrm{~mm} \\
\mathrm{fy} & =360 \mathrm{Mpa} \\
\mathrm{f}^{\prime} \mathrm{c} & =21 \mathrm{Mpa} \quad b=1200 \mathrm{~mm}
\end{aligned}
$$

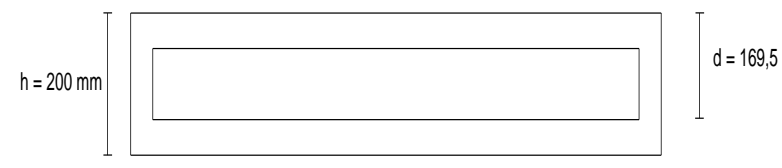

Gambar 2: Dimensi Tulangan Tangga

Untuk pelat digunakan :

$$
\begin{aligned}
\checkmark \rho b & =\frac{0,85 \times f^{\prime}}{f y} \times \beta \times\left(\frac{600}{600+f y}\right) \\
& =\frac{0,85 \times 21}{360} \times 0,85 \times\left(\frac{600}{600+360}\right) \\
& =0,0263
\end{aligned}
$$




$$
\begin{aligned}
\checkmark \text { pmax } & =0,75 \times \rho b \\
& =0,75 \times 0,0263 \\
& =0,0197 \\
\checkmark \quad \rho \min & =\frac{1,4}{\mathrm{fy}} \\
& =\frac{1,4}{360} \\
& =0,0039 \\
\checkmark \mathrm{Mu} & =1 / 8 \times \mathrm{wu} \times \mathrm{L}^{2}+1 / 4 \times \mathrm{pu} \times \mathrm{L} \\
& =1 / 8 \times 1264,8 \times 12^{2}+1 / 4 \times 80 \times 12 \\
& =23006,4 \mathrm{~kg} / \mathrm{m}=23,006400 \mathrm{~N} / \mathrm{mm}
\end{aligned}
$$

$\checkmark \mathrm{Mn}=\frac{\mathrm{Mu}}{\Phi}$

$=\frac{23,006400}{0,8}$

$=28,758000 \mathrm{~N} / \mathrm{mm}$

$\checkmark \mathrm{m}=\frac{\mathrm{fy}}{0,85 \times \mathrm{fcc}}=\frac{360}{0,85 \times 21}$

$=20,1681 \mathrm{~N} / \mathrm{mm}$

$\checkmark \mathrm{Rn}=\frac{\mathrm{Mn}}{\mathrm{bxd}^{\wedge} 2}=\frac{28,758000}{1200 \times 169,5^{\wedge} 2}$

$=8,3414 \mathrm{~N} / \mathrm{mm}$

$\checkmark \rho=\frac{1}{\mathrm{~m}} 1-\sqrt{1-\frac{2 \times m \times R n}{f y}}$

$=\frac{1}{20,1681} 1-\sqrt{1-\frac{2 \times 20,1681 \times 8,3414}{360}}$

$=0,0496 \times 0,744$

$=0,0370$

Maka $\rho \min <\rho<\rho \max$

Dipaki $\rho=0,0370$

As $\quad=\rho \times \mathrm{bxd}$

$=0,0370 \times 1200 \times 169,5$

$=752,58 \mathrm{~mm}^{2}$

Asmin $=0,25 \% \times \mathrm{b} \times \mathrm{h}=0,0025 \times 1200 \times 200$

$$
=600 \mathrm{~mm}^{2}
$$

Dipakai tulangan $\phi \mathrm{u}-13 \mathrm{~mm}$

$$
\begin{aligned}
& =1 / 4 \times \pi \times D 13^{2} \\
& =1 / 4 \times 3,14 \times 169 \\
& =132,67 \mathrm{~mm}^{2}
\end{aligned}
$$

Jumlah Tulangan (n)

$$
=\frac{\text { As }}{\text { Tul.dipakai }}=\frac{752,58}{132,67}=5,67 \approx 6 \text { buah }
$$

Jarak Tulangan

$$
=\frac{\text { Lebar Tangga }}{\mathrm{n}}=\frac{1200}{6}=200 \mathrm{~mm}
$$

Jarak Maksimum Tulangan

$$
=2 \times 200=400 \mathrm{~mm}
$$

Dipakai Diameter tulangan D13 mm - $200 \mathrm{~mm}$

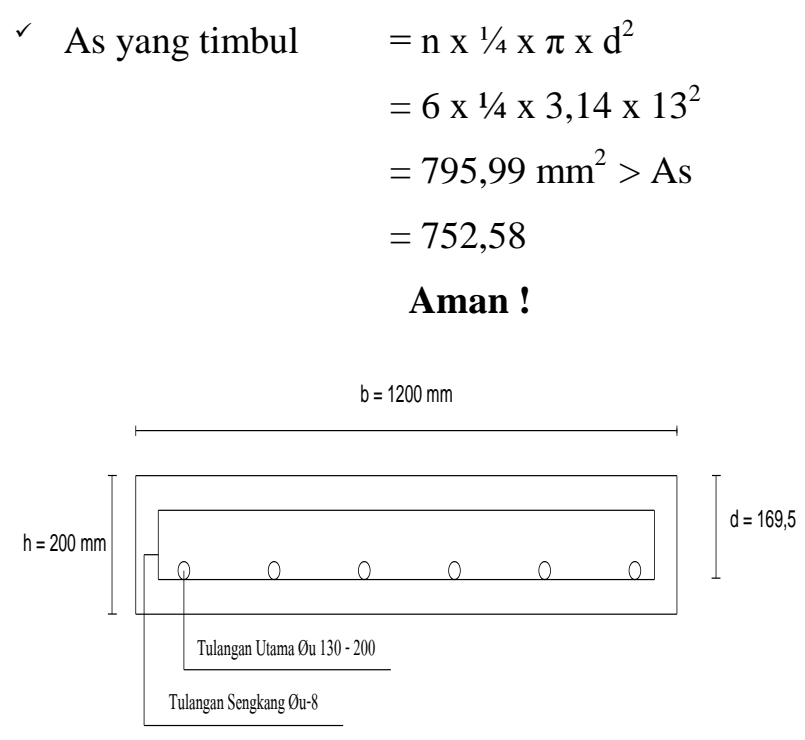

Gambar 3. Detail Tulangan Tangga

\section{F. PERHITUNGAN TULANGAN BORDES}

Data:b $\quad=2850 \mathrm{~mm}$

$\mathrm{h} \quad=1420 \mathrm{~mm}$

d $\quad=\mathrm{h}-\mathrm{p}-1 / 2$ Dtul

$=1420-20-1 / 213-1 / 28$

$$
\begin{aligned}
& =1389,5 \mathrm{~mm} \\
\text { Fy } & =360 \mathrm{Mpa} \\
\text { F'c } & =21 \mathrm{Mpa}
\end{aligned}
$$

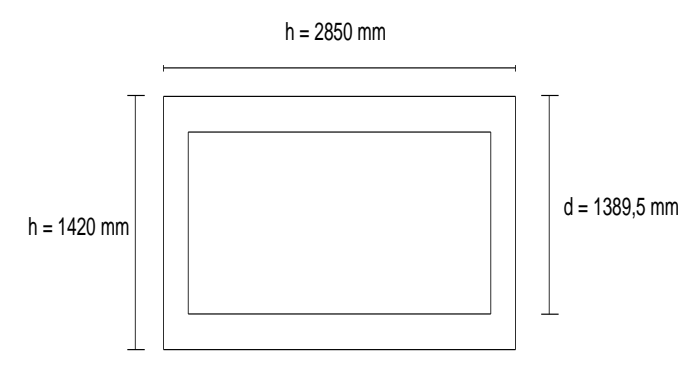

Gambar 4: Tulangan Bordes 
Untuk pelat digunakan :

$$
\begin{aligned}
\rho \mathrm{b} & =\frac{0,85 * \mathrm{fc}^{\prime}}{\mathrm{fy}} \times \beta \times\left(\frac{600}{600+\mathrm{fy}}\right) \\
& =\frac{0,85 * 21}{360} \times 0,85 \times\left(\frac{600}{600+360}\right) \\
& =0,0263 \\
\rho \max & =0,75 \times \rho \mathrm{b} \\
& =0,75 \times 0,0263 \\
& =0,0197 \\
\rho \min & =\frac{1,4}{\mathrm{fy}} \\
& =\frac{1,4}{360} \\
& =0,0039 \\
\mathrm{Mu} & =1 / 8 \times \mathrm{wu} \times \mathrm{L}^{2}+1 / 4 \times \mathrm{pu} \times \mathrm{L} \\
& =1 / 8 \times 1120,8 \times 28,5^{2}+1 / 4 \times 80 \times 28,5 \\
& =114366,23 \mathrm{~kg} / \mathrm{m} \\
& =11436623 \mathrm{~N} / \mathrm{mm}
\end{aligned}
$$

$$
\begin{aligned}
\checkmark \mathrm{Mn} & =\frac{\mathrm{Mu}}{\Phi} \\
& =\frac{11436623}{0,8} \\
& =14295778 \mathrm{~N} / \mathrm{mm} \\
\checkmark \mathrm{m} & =\frac{\mathrm{fy}}{0,85 \times \mathrm{fc}^{\prime}}=\frac{360}{0,85 \times 21}=20,17 \mathrm{~N} / \mathrm{mm} \\
\checkmark \mathrm{Rn} & =\frac{\mathrm{Mn}}{{\mathrm{b} \times \mathrm{d}^{\wedge} 2}}=\frac{14295778}{2850 \times 1389,5^{\wedge} 2} \\
& =0,0026 \mathrm{~N} / \mathrm{mm} \\
\checkmark & =\frac{1}{\mathrm{~m}} 1-\sqrt{1-\frac{2 \times m \times R n}{f y}} \\
& =\frac{1}{20,17} 1-\sqrt{1-\frac{2 \times 20,17 \times 0,0026}{360}} \\
& =0,0496 \times 0,01 \\
& =0,000496
\end{aligned}
$$

Dipaki $\rho=0,000496$

$$
\begin{aligned}
\checkmark \text { As } & =\rho \times \mathrm{b} \times \mathrm{d} \\
& =0,000496 \times 2850 \times 1389,5 \\
& =1964,20 \mathrm{~mm}^{2}
\end{aligned}
$$

Asmin $=0,25 \% \times \mathrm{b} \mathrm{xh}$

$$
\begin{aligned}
& =0,0025 \times 2850 \times 1420 \\
& =10117,5 \mathrm{~mm}^{2}
\end{aligned}
$$

Dipakai tulangan D13 mm

$$
\begin{aligned}
& =1 / 4 \times \pi \times D 13^{2} \\
& =1 / 4 \times 3,14 \times 169 \\
& =132,67 \mathrm{~mm}^{2}
\end{aligned}
$$

Jumlah Tulangan

$$
\begin{aligned}
& =\frac{\text { As }}{\text { Tul.dipakai }}=\frac{1964,20}{132,67} \\
& =14,81 \approx 15 \text { buah }
\end{aligned}
$$

Jarak Tulangan $=\frac{\text { Lebar Bordes }}{\text { jumlah tulangan }}$

$$
\begin{aligned}
& =\frac{2850}{15} \\
& =190 \mathrm{~mm}
\end{aligned}
$$

Jarak Maksimum Tulangan

$$
=2 \times 190=380 \mathrm{~mm}
$$

$\checkmark \quad$ Dipakai Diameter tulangan D13 mm - 200 $\mathrm{mm}$

As yang timbul $=n \times 1 / 4 \times \pi \times d^{2}$

$$
\begin{aligned}
& =15 \times 1 / 4 \times 3,14 \times 13^{2} \\
& =1989,98 \mathrm{~mm}^{2}>\mathrm{As} \\
& =1964,20
\end{aligned}
$$

\section{Aman !}

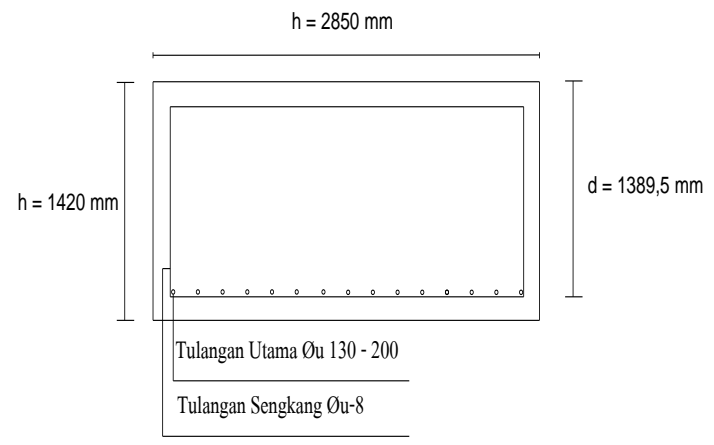

Gambar 4.4 Detail Tulangan Bordes

\section{G. Menghitung Volume Beton Tangga}

1. Volume Anak Tangga

Volume 1 Anak Tangga

$=(($ Injakan $\mathrm{x}$ Tanjakan $): 2) \times$ Lebar Tangga 


$$
\begin{aligned}
& =((0,30 \mathrm{~m} \times 0,18 \mathrm{~m}): 2) \times 1,2 \\
& =0,0324 \mathrm{~m}^{3}
\end{aligned}
$$

Dari jumlah anak tangga yang sudah dihitung sebelumnya ada 42 anak tangga maka untuk volume seluruh anak tangga adalah $42 \mathrm{x}$ $0,0324=1,3608 \mathrm{~m}^{3}$

2. Volume Plat Lantai Tangga

Volume Plat

$=$ Lebar Tangga $\mathrm{x}$ Tebal Plat $\mathrm{x}$ Panjang

$=1,2 \times 0,2 \times(11,30 \times 4)$

$$
=10,848 \mathrm{~m}^{3}
$$

Maka jumlah kebutuhan volume beton pada tangga adalah

= volume anak tangga + volume plat tangga

$=1,3608+10,848$

$=12,2088 \mathrm{~m}^{3}$

\section{KESIMPULAN}

Pembangunan RSUD Cidere Majalengka tersebut dan menarik kesimpulan tentang analisa yang saya tinjau, adapun kesimpulannya adalah sebagai berikut :

1. Struktur Tangga terdapat Untuk tinggi dan lebar anak tangga yang sangat menentukan kenyamanan, sehingga orang yang naik tidak cepet lelah dan orang yang turun tidak mudah tergelincirt idak sesuai dengan perhitungan atau standar ideal dari perencanaan tinggi dan lebar pada suatu anak tangga $2 \mathrm{t}+1=2 *(18)+30=66 \mathrm{~cm}$ yang harusnya adalah $60-65 \mathrm{~cm}$.

2. Dengan injakan $30 \mathrm{~cm}$, tanjakan $18 \mathrm{~cm}$, dan tinggi total keseluruhan adalah $8 \mathrm{~m}$ maka Total anak tangga adalah 42 buah Anak Tangga, dari nilai tersebut terdapat selisih maka beda tinggi anak tangga di letakan pada satu anak tangga yang paling bawah atau paling atas.

3. Dalam perhitungan kebutuhan tulangan pada tangga dan bordes dengan menggunakan D13-200 dibutuhkan enam tulangan untuk tangga dan lima belas tulangan untuk bordes.
4. Dengan luas tulangan yang di dapatkan dari pergitungan tangga dan bordes hasil yang di dapat aman.

\section{DAFTAR PUSTAKA}

Badan Standardisasi Nasional. 2002. Rancangan Standar Nasional Indonesia Tata Cara Perencanaan Struktur Beton untuk Bangunan Gedung.

Badan Standardisasi Nasional. 2003. Standar Nasional Indonesia Tata Cara Perencanaan Ketahanan Gempa untuk Bangunan Gedung SNI-17262003.

Departemen Pekerjaan Umum. 1991. Tata Cara Perhitungan Struktur Beton untuk Bangunan Gedung SKSNI T-15-199103.

Mosley, W.H dan Bungey, J.H. 1987. Perencanaan Beton Bertulang. Jakarta: Penerbit Erlangga.

Nawi, Edward G. 1998. Beton Bertulang: Suatu Pendekatan Dasar. Bandung: PT Refika Aditama. (penerjemah: Suryoatmono, Bambang)

Udiyanto. 2000. Menghitung Beton Bertulang. Semarang: Divisi Penerbitan Biro Pengembangan Profesionalisme Sipil Universitas Diponegoro

Vis,W.C dan Kusuma,Gideon H. 1997. Dasardasar Perencanaan Beton Bertulang. Jakarta: Penerbit Erlangga

Vis,W.C dan Kusuma,Gideon H. 1993. Grafik dan Tabel Perhitungan Beton Bertulang. Jakarta: Penerbit Erlangga 